\title{
The Rice Bacterial Pathogen Xanthomonas oryzae pv. oryzae Produces 3-Hydroxybenzoic Acid and 4-Hydroxybenzoic Acid via XanB2 for Use in Xanthomonadin, Ubiquinone, and Exopolysaccharide Biosynthesis
}

\author{
Lian Zhou, ${ }^{1}$ Tin-Wei Huang, ${ }^{1}$ Jia-Yuan Wang, ${ }^{1}$ Shuang Sun, ${ }^{1}$ Gongyou Chen, ${ }^{2}$ Alan Poplawsky, ${ }^{3}$ and \\ Ya-Wen $\mathrm{He}^{1}$ \\ ${ }^{1}$ State Key Laboratory of Microbial Metabolism and National Center for Molecular Characterization of GMOs, School of Life \\ Sciences \& Biotechnology, Shanghai Jiao Tong University, Shanghai 200240, China; ${ }^{2}$ School of Agriculture \& Biology, \\ Shanghai Jiao Tong University, Shanghai 200240, China; ${ }^{3}$ Department of Plant, Soil \& Entomological Sciences, University \\ of Idaho, Moscow 83844-2339, U.S.A.
}

Submitted 22 April 2013. Accepted 22 May 2013.

Xanthomonas oryzae pv. oryzae, the causal agent of rice bacterial blight, produces membrane-bound yellow pigments, referred to as xanthomonadins. Xanthomonadins protect the pathogen from photodamage and host-induced perioxidation damage. They are also required for epiphytic survival and successful host plant infection. Here, we show that XanB2 encoded by PXO_3739 plays a key role in xanthomonadin and coenzyme Q8 biosynthesis in $X$. oryzae pv. oryzae PXO99A. A xanB2 deletion mutant exhibits a pleiotropic phenotype, including xanthomonadin deficiency, producing less exopolysaccharide (EPS), lower viability and $\mathrm{H}_{2} \mathrm{O}_{2}$ resistance, and lower virulence. We further demonstrate that $X$. oryzae pv. oryzae produces 3-hydroxybenzoic acid (3-HBA) and 4-hydroxybenzoic acid (4-HBA) via XanB2. 3-HBA is associated with xanthomonadin biosynthesis while 4-HBA is mainly used as a precursor for coenzyme $\mathrm{Q}(\mathrm{CoQ}) 8$ biosynthesis. XanB2 is the alternative source of 4-HBA for CoQ8 biosynthesis in PXO99A. These findings suggest that the roles of XanB2 in PXO99A are generally consistent with those in $X$. campestris pv. campestris. The present study also demonstrated that $X$. oryzae pv. oryzae PXO99A has evolved several specific features in 3-HBA and 4-HBA signaling. First, our results showed that PXO99A produces less 3-HBA and 4-HBA than $X$. campestris pv. campestris and this is partially due to a degenerated 4-HBA efflux pump. Second, PXO99A has evolved unique xanthomonadin induction patterns via 3-HBA and 4-HBA. Third, our results showed that 3-HBA or 4-HBA positively regulates the expression of gum cluster to promote EPS production in PXO99A. Taken together, the results of this study indicate that XanB2 is a key metabolic enzyme linking xan-

\section{Zhou and T. W. Huang contributed equally to this work.}

Corresponding author: Y.-W. He; Telephone: +86-21-34207941; Fax: +86-21-34205709; E-mail: yawenhe@ sjtu.edu.cn

* The $\boldsymbol{e}$-Xtra logo stands for "electronic extra" and indicates that eleven supplementary figures are published online and that Figures 1 and 8 appear in color online.

(C) 2013 The American Phytopathological Society thomonadin, CoQ, and EPS biosynthesis, which are collectively essential for $X$. oryzae pv. oryzae pathogenesis.

Xanthomonas is a genus of gram-negative, polarly flagellated, phytopathogenic bacteria. These bacteria infect nearly 400 different plant hosts, including economically important crops such as rice, cotton, soybean, oil-rape, citrus, and banana (Leyns et al. 1984). A characteristic feature of this genus is the production of yellow, membrane-bound pigments called xanthomonadins (Starr 1981). Xanthomonadins are mixtures of unusual brominated, aryl-polyene esters (Andrewes et al. 1976; Stephens and Starr 1963), and xanthomonadins from different Xanthomonas spp. differ in bromination and methylation patterns (Starr et al. 1977). In addition to being a diagnostic characteristic of the genus (Starr 1981), xanthomonadins may protect Xanthomonas spp. from photobiological and peroxidation damage induced by host defense mechanisms (He et al. 2011; Jenkins and Starr 1982; Poplawsky et al. 2000; Rajagopal et al. 1997) and are required for epiphytic survival and host infection (Goel et al. 2001; He et al. 2011; Park et al. 2009; Poplawsky et al. 2000). These findings have established the role of xanthomonadins in maintaining the ecological fitness and virulence of Xanthomonas spp.

A diffusible factor (DF) has been implicated in the regulation of xanthomonadin production and extracellular polysaccharide (EPS) in Xanthomonas campestris pv. campestris B-24 (Poplawsky and Chun 1997). Subsequent investigation showed that XCC4014 (renamed as xanB2) in X. campestris pv. campestris ATCC33913 is required for DF biosynthesis (Poplawsky et al. 2005). Moreover, disruption of $x a n B 2$ abolishes xanthomonadins and DF production in $X$. campestris pv. campestris strains B-24, 8004, and XC1 (He et al. 2011; Poplawsky and Chun 1997). The DF produced by $X$. campestris pv. campestris strains 8004 and XC1 has been purified and chemically characterized as 3-hydroxybenzoic acid (3-HBA) (He et al. 2011). Genetic and biochemical analysis showed that 3-HBA is associated with bacterial survival, cell viability, $\mathrm{H}_{2} \mathrm{O}_{2}$ resistance, and systemic invasion (He et al. 2011).

Numerous bacterial species within the genera Xanthomonas, Xylella, Xylophilus, and Burkholderia also display DF-like 
activity. An even wider range of bacterial genomes contain homologs of $x a n B 2$ (He et al. 2011). These findings suggest that the biosynthesis and biological functions of DF are widely conserved in bacteria (He et al. 2011). Previously, XanB2 was predicted to be a putative pteridine-dependent deoxygenase (da Silva et al. 2002). Recent results describe XanB2 as a novel bifunctional chorismatase that hydrolyzes chorismate to produce 3-HBA and 4-hydroxybenzoic acid (4-HBA). 3-HBA is associated with the yellow xanthomonadin biosynthesis, whereas the XanB2-derived 4-HBA is a precursor for coenzyme Q (CoQ)8 biosynthesis (Zhou et al. 2013). Furthermore, along with XanB2, the shikimate pathway, xanthomonadin biosynthetic cluster, and ubiquinone biosynthetic pathway are found in all Xanthomonas spp., Xylella fastidiosa, and Xylophilus ampelinus, suggesting that XanB2 may act as a widely conserved metabolic link in these bacterial pathogens (Zhou et al. 2013).

The shikimate pathway is widely present in plants, bacteria, and fungi (Herrmann and Weaver 1999). The end product of the shikimate pathway is chorismate, which is the common precursor for the biosynthesis of aromatic amino acids and other aromatic compounds such as folate cofactors, phenazines, siderophores, salicylic acid, and hydroxybenzate (Andexer et al. 2011; Dosselaere and Vanderleyden 2001; Herrmann and Weaver 1999; Van Lanen et al. 2008; Zhou et al. 2013). CoQ is a naturally occurring coenzyme formed by the conjugation of a benzoquinone ring with a hydrophobic isoprenoid chain of varying length (Cluis et al. 2007). It is an obligatory cofactor in the aerobic respiratory electron transfer for energy generation. It also acts as an antioxidant that protects membrane phospholipids and proteins from lipid peroxidation by scavenging free radicals directly or by regenerating levels of tocopherol (Cluis et al. 2007; Martin et al. 2007). The CoQ biosynthetic pathway in Escherichia coli consists of at least nine enzymes, including UbiA, UbiB, UbiC, UbiD, UbiE, UbiF, UbiG, UbiH, and IspB (Bentinger et al. 2010; Meganathan 2001). The formation of 4-HBA from chorismate is the first committed step, which is catalyzed by chorismate-pyruvate lyase encoded by ubiC in E. coli or by Rv2949c in Mycobacteria (Siebert et al. 1994; Sǿballe and Poole, 1999; Stadthagen et al. 2005). Our previous results showed that Xanthomonas campestris pv. campestris lacks the genes encoding chorismate-pyruvate lyase and XanB2 is a novel chorismatase to provide an alternative source of 4-HBA for CoQ8 production (Zhou et al. 2013).

$X$. oryzae pv. oryzae is a rod-shaped, gram-negative bacterium (Nino-Liu et al. 2006). It causes one of the most serious diseases in rice, bacterial blight. $X$. oryzae pv. oryzae colonies are round, convex, and mucoid on solid media that contains glucose. The colonies present yellow in color due to the production of the pigment xanthomonadin (Bradbury 1984). Goel and associates (2001) characterized a 21.0-kb genomic region involved in xanthomonadin biosynthesis in the $X$. oryzae pv. oryzae $\mathrm{BXO} 1$, and further analysis showed that xanthomonadin might be synthesized through a novel type II polyketide pathway. The detailed chemical structures of xanthomonadins in $X$. oryzae pv. oryzae have yet to be elucidated. Studies suggest that xanthomonadins may be some of the most important virulence factors in $X$. oryzae pv. oryzae. Disruption of xanthomonadin biosynthesis led to a virulence deficiency in a previous study (Goel et al. 2001; Park et al. 2009; Song et al. 2011). In addition, xanthomonadin appears to protect $X$. oryzae pv. oryzae against photooxidative damage (Rajagopal et al. 1997).

DF-like activity has previously been detected in $X$. oryzae pv. oryzae strains PXO99A, HB21, and KACC10331 (Chun et al. 1997; He et al. 2011). A homolog of $x a n B 2$ has also been found in the genomes of $X$. oryzae pv. oryzae strains PXO99A,
KACC10331, and MAFF 311018 (He et al. 2011). Moreover, mutations in genes involved in the shikimate pathway lead to deficiency in pigments (Goel et al. 2001; Park et al. 2009; Song et al. 2011). These findings suggest that $X$. oryzae pv. oryzae might use a similar mechanism in DF biosynthesis and DF-dependent xanthomonadin and ubiquinone biosynthesis. To this end, the biological functions of $x a n B 2$ and DF in the rice pathogen $X$. oryzae pv. oryzae PXO99A were investigated. Our results indicate the biological functions of $x a n B 2$ and DF in $X$. oryzae pv. oryzae are similar to those in $X$. campestris pv. campestris. In addition, results of the present study suggest that $X$. oryzae pv. oryzae has evolved several unique features in DF signaling.

\section{RESULTS}

\section{A $x a n B 2$ deletion mutant confers pleiotropic phenotypes in $X$. oryzae pv. oryzae PXO99A.}

Previously, xanthomonadins were shown to be synthesized via the products of the pig cluster in $X$. campestris pv. campestris (Supplementary Fig. S1). Among the pig cluster, XCC4014 (xanB2) was responsible for 3-HBA and 4-HBA biosynthesis (He et al. 2011; Poplawsky et al. 2005; Zhou et al. 2013). The X. oryzae pv. oryzae wild-type strain PXO99A contained two loci with 20 open reading frames (PXO_2878 to PXO_2885 and PXO_3729 to PXO_3741, respectively). They are highly homologous to the pig cluster in $X$. campestris pv. campestris, suggesting that $X$. oryzae pv. oryzae might use a similar mechanism for xanthomonadin biosynthesis. To investigate this hypothesis, a PXO_3739 (a xanB2 homolog) deletion mutation strain was created in PXO99A. The resulting mutation strain failed to produce xanthomonadins. However, the in trans overexpression of PXO_3739 restored xanthomonadin production (Fig. 1A and $\mathrm{B}$ ). These findings confirm that PXO_3739, similar to its homolog xanB2, is involved in xanthomonadin biosynthesis. Therefore, PXO_3739 was also renamed as $x a n B 2$ in this study.

Strain $\triangle \mathrm{xanB} 2$ was further analyzed for other phenotypes. Disruption of $x a n B 2$ did not affect in vitro growth in sucrosecontaining peptone-yeast-sucrose (NAS) liquid medium or glycerol-containing peptone-yeast-glycerol (NYG) medium (Supplementary Fig. S2). EPS levels found in the supernatant of the mutant strain $\Delta \mathrm{xanB} 2$ were $2.3 \mathrm{mg} / \mathrm{ml}$ at late stationary phase (optical density at $600 \mathrm{~nm}\left[\mathrm{OD}_{600}\right]=2.3$ ). This level was significantly lower than EPS at $3.2 \mathrm{mg} / \mathrm{ml}$ produced by the wild-type strain PXO99A (Fig. 2A). Moreover, in trans overexpression of $x a n B 2$ in $\triangle \mathrm{xanB} 2$ strain restored EPS production to above wild-type levels (Fig. 2A).

The cell viability of PXO99A and derivatives were compared by counting CFU at different growth stages during a time course. No significant differences in viability were observed between the wild type and $x a n B 2$ mutants during the exponential phase of bacterial growth $\left(\mathrm{OD}_{600}=1.2\right)$ (Fig. 3A). However, the viability of the $x a n B 2$ mutant at early and late stationary phases $\left(\mathrm{OD}_{600}=2.0\right.$ and 2.3, respectively) was significantly lower than that of wild-type PXO99A (Fig. 3A). In trans overexpression of $x a n B 2$ in the $\triangle \mathrm{xanB} 2$ strain restored CFU viability to that of wild-type strains in stationary phase (Fig. 3A).

To assay oxidative stress resistance, $X$. oryzae pv. oryzae strains were grown in NAS medium until they reached the early stationary phase $\left(\mathrm{OD}_{600}=2.0\right)$. Next, the bacterial cells were precipitated and the pellet was resuspended in fresh NAS medium and put to the same density level. Hydrogen peroxide $\left(\mathrm{H}_{2} \mathrm{O}_{2}\right)$ was then added to the cultures at final concentrations of 440 and $880 \mu \mathrm{M}$, respectively. After $30 \mathrm{~min}$ of $\mathrm{H}_{2} \mathrm{O}_{2}$ treatment, the CFU values of each strain were compared. The results showed that deletion of $x a n B 2$ substantially decreased bacte- 
rial resistance to oxidative stress, as indicated by lower $\mathrm{CFU}$ values for the $\Delta$ xanB2 strain with $\mathrm{H}_{2} \mathrm{O}_{2}$ treatment. Furthermore, overexpression of $x a n B 2$ restored $\mathrm{H}_{2} \mathrm{O}_{2}$ resistance in the $\Delta \mathrm{xanB} 2$ strain to close to wild-type levels (Fig. 4).

\section{A}

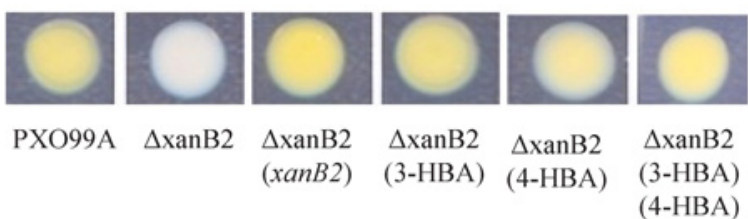

B

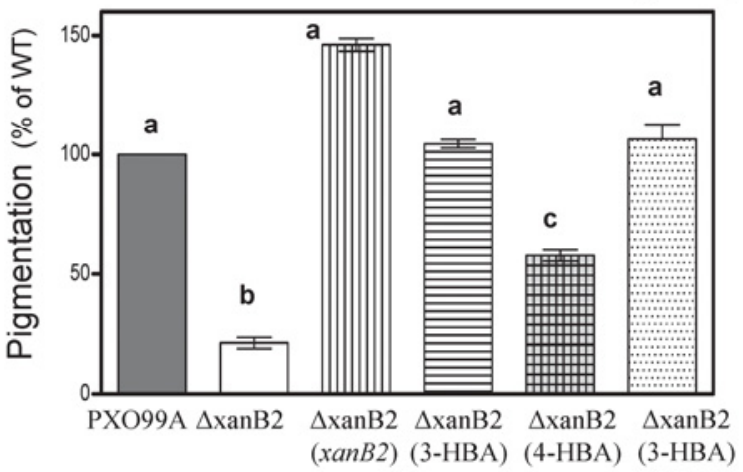

C

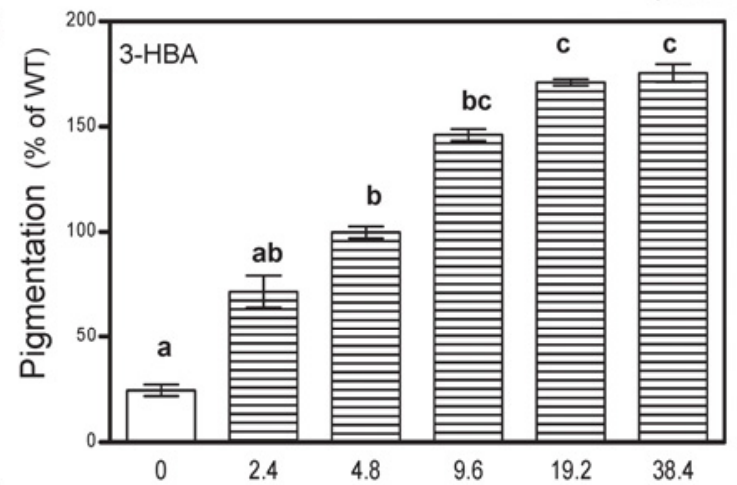

D

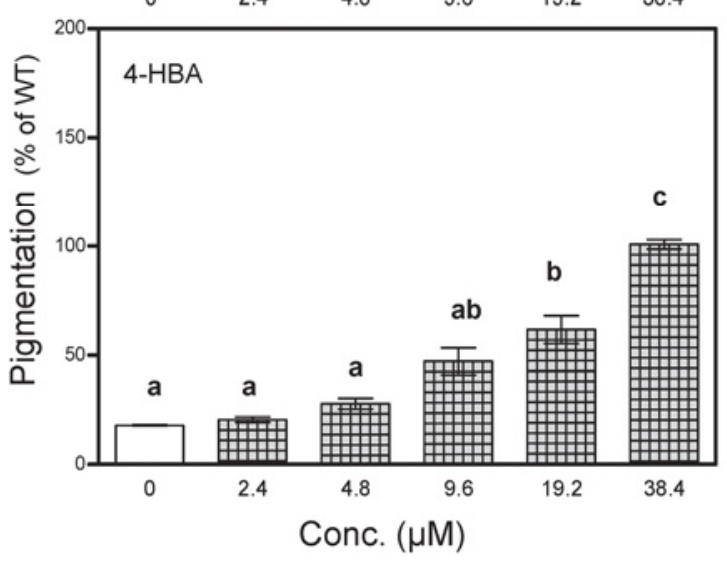

Fig. 1. Reduced xanthomonadin production of the Xanthomonas oryzae pv. oryzae PXO99A $\Delta \mathrm{xanB} 2$ strain and restoration by xanB2, 3-hydroxybenzoic acid (3-HBA), and 4-hydroxybenzoic acid (4-HBA). A, Yellow pigmentation of $X$. oryzae pv. oryzae strains. B, Quantitative analysis of xanthomonadin production in $X$. oryzae pv. oryzae strains. C, Effect of increasing concentrations of 3-HBA on the xanthomonadin production of the $\Delta \mathrm{xanB} 2$ strain $\mathbf{D}$, Effect of increasing concentrations of 4-HBA on the xanthomonadin production of the $\Delta x a n B 2$ strain. $(x a n B 2)=$ complemented with a plasmid pBBRMCS1 harboring the gene $x a n B 2 .(3-\mathrm{HBA})=$ addition of 3-HBA at a final concentration of $4.8 \mu \mathrm{M}$. (4-HBA) = addition of 4-HBA at a final concentration of $38.4 \mu \mathrm{M}$. WT indicates $X$. oryzae pv. oryzae PXO99A grown in a medium without 3-HBA and 4-HBA. Values shown are the means \pm standard deviation from three independent experiments. Different letters indicate significant difference between treatments according to least significant difference at $P=0.05$.
Finally, the virulence of wild-type strain PXO99A, the $\Delta \mathrm{xanB} 2$ strain, and the complemented strain was evaluated by measuring lesion lengths on rice plant leaves at 14 days post inoculation. The mean lesion length observed with the $\Delta \mathrm{xanB} 2$ strain was significantly reduced by approximately $3.5 \mathrm{~cm}$ compared with that observed with wild-type strain PXO99A (Fig. 5). These results demonstrate that $x a n B 2$ is required for full virulence of $X$. oryzae pv. oryzae in rice. Consistently, the populations of strain $\Delta x a n B 2$ on adult rice leaves were significantly lower than those of PXO99A at weeks 1 and 2 (Fig. 5B). Overexpression of $x a n B 2$ restored the populations to wild-type levels (Fig. 5B).
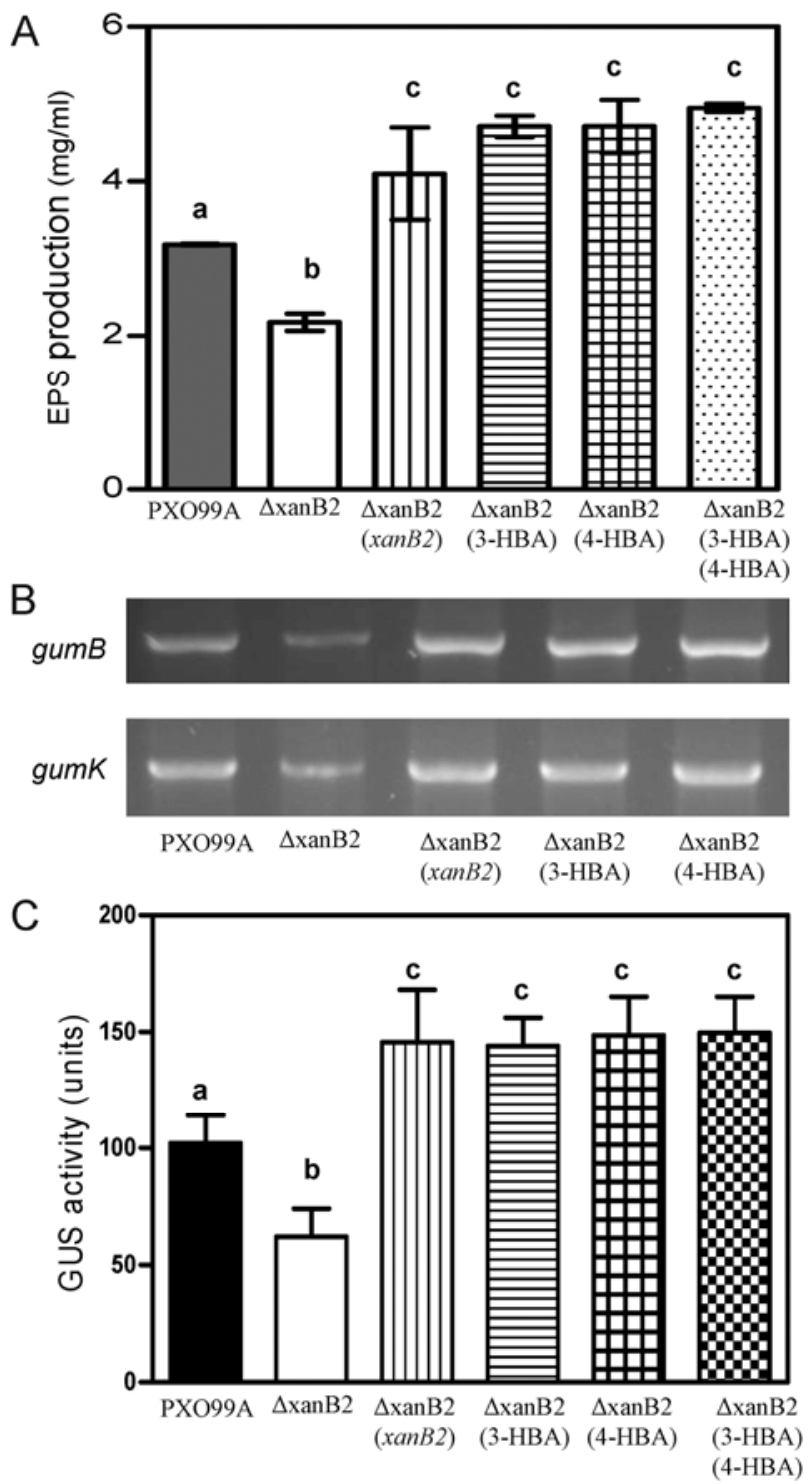

Fig. 2. Effects of $x a n B 2$, 3-hydroxybenzoic acid (3-HBA), and 4-hydroxybenzoic acid (4-HBA) on extracellular polysaccharide (EPS) production in Xanthomonas oryzae pv. oryzae PXO99A $\triangle \mathrm{xanB} 2$ strain. A, Overexpression of $x a n B 2$, or the exogenous addition of 3-HBA $(19.2 \mu \mathrm{M})$ or 4-HBA $(19.2 \mu \mathrm{M})$ restores EPS production to the $\triangle \mathrm{xanB} 2$ strain. B, Reverse-transcription polymerase chain reaction analysis of gumB and gumK expression. C, $\beta$-Glucuronidase (GUS) activity of PXO99A strains in the presence of 3-HBA or 4-HBA. (xanB2) = complemented with a plasmid pBBRMCS1 harboring the gene $x a n B 2$. (3-HBA) = addition of 3-HBA at a final concentration of $19.2 \mu \mathrm{M}$. (4-HBA) $=$ addition of 4-HBA at a final concentration of $19.2 \mu \mathrm{M}$. Values shown are the means \pm standard deviation from three independent experiments. Different letters indicate significant difference between treatments according to least significant difference at $P=0.05$. 
PXO99A produces 3-HBA and 4-HBA via XanB2.

Using the previously described method for 3-HBA and 4HBA extraction and purification in $X$. campestris pv. campestris (He et al. 2011; Zhou et al. 2013), two compounds were identified from the supernatants of $X$. oryzae pv. oryzae PXO99A. These two compounds were chemically characterized as 3-HBA and 4-HBA based on UV absorbance, elution time in high-performance liquid chromatography (HPLC) analysis, mass spectrometry (MS) analysis, and in vitro pigment-induction assay (Figs. 1 and 6A and B; Supplementary Fig. S3). Furthermore, our results demonstrated that 3-HBA and 4-HBA production was cell-density dependent, with the maximum levels in the supernatant of PXO99A cell cultures being 1.2 and $1.1 \mu \mathrm{M}$, respectively (Fig. 6C). Deletion of $x a n B 2$ completely abolished 3-HBA and 4-HBA production while overexpression of $x a n B 2$ in strain $\triangle \mathrm{xanB} 2$ restored 3 -HBA and 4-HBA production (Fig. $6 \mathrm{~B})$. These findings show that XanB2 is required for 3-HBA and 4-HBA production in X. oryzae pv. oryzae PXO99A.

\section{The differential effects of 3-HBA and 4-HBA} on xanthomonadin induction in PXO99A.

Exogenous addition of 3 -HBA to the $\Delta$ xanB2 strain fully restored xanthomonadin production (Fig. 1C). The color of 3-HBA-induced pigment was similar to that of the wild-type
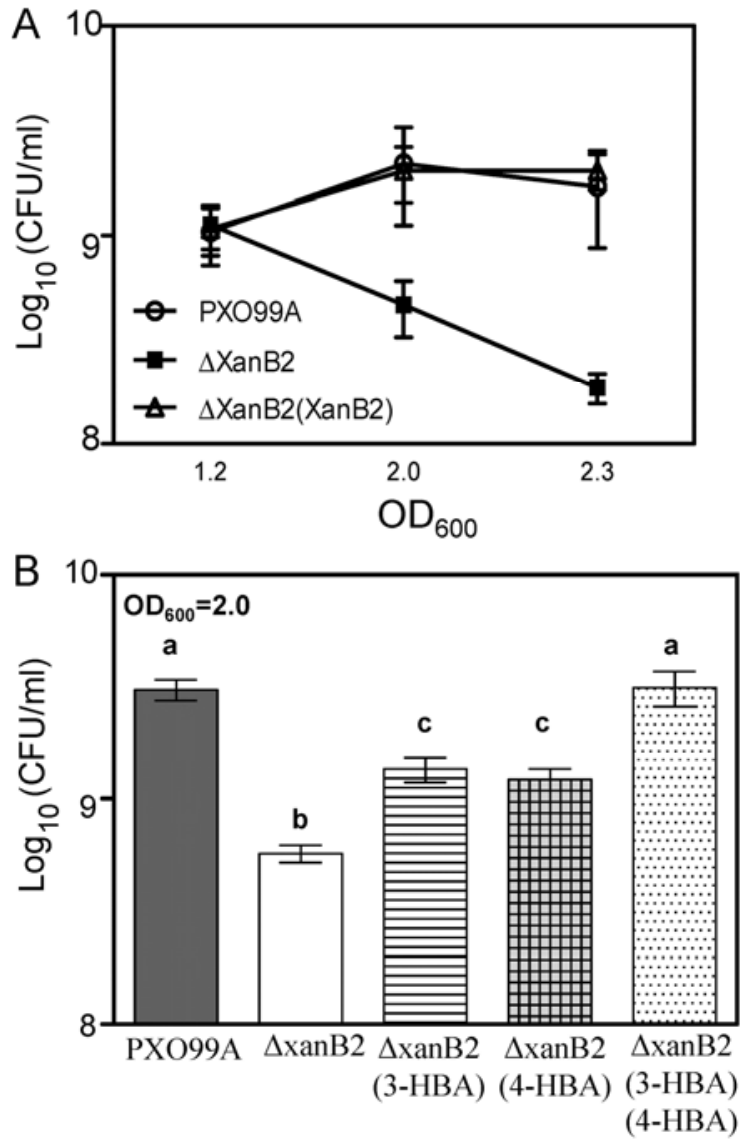

Fig. 3. Effects of $x a n B 2$, 3-hydroxybenzoic acid (3-HBA), and 4-hydroxybenzoic acid (4-HBA) on cell viability of Xanthomonas oryzae pv. oryzae PXO99A $\Delta$ xanB2 strain. A, CFU of Xanthomonas oryzae pv. oryzae strains at different growth stages. B, Effect of exogenous addition of 3 -HBA or 4-HBA on the viability of the $\triangle \mathrm{xanB} 2$ strain. $($ xanB2 $)=$ complemented with a plasmid pBBRMCS1 harboring the gene $x a n B 2$. $(3-\mathrm{HBA})=$ addition of 3-HBA at a final concentration of $4.8 \mu \mathrm{M}$. (4-HBA) $=$ addition of 4-HBA at a final concentration of $38.4 \mu \mathrm{M}$. Values shown are the means \pm standard deviation from three independent experiments. Different letters indicate significant difference between treatments according to least significant difference at $P=0.05$. strain (Fig. 1A). In addition, xanthomonadin production increased as the exogenous concentration of 3-HBA increased, ranging from $99.0 \%$ of the wild type at $4.8 \mu \mathrm{M}$ to $175.5 \%$ at $38.4 \mu \mathrm{M}$ (Fig. 1C). In contrast, the exogenous addition of 4 -HBA induced the $\Delta x a n B 2$ strain to produce atypical paleyellow pigments (Fig. 1A). The minimum concentration of 4-HBA for full wild-type level of pigment induction was $38.4 \mu \mathrm{M}$ (Fig. 1D). Further increasing the concentration of 4-HBA above $38.4 \mu \mathrm{M}$ did not significantly increase pigment production (data not shown). Finally, when 3-HBA $(4.8 \mu \mathrm{M})$ and 4 -HBA $(38.4 \mu \mathrm{M})$ were both added to the $\Delta$ xanB2 strain, xanthomonadin induction was similar to that of the wild-type strain (Fig. 1A). These findings suggest that 3-HBA is of greater biological importance for xanthomonadin biosynthesis in $X$. oryzae pv. oryzae.

\section{3-HBA or 4-HBA is required for full EPS induction.}

The above findings suggest that 3-HBA or 4-HBA is required for full EPS production. To explore these possibilities, 3-HBA or $4-\mathrm{HBA}$ was added to the $\triangle \mathrm{xanB} 2$ strain at early growth phase $\left(\mathrm{OD}_{600}=0.4\right)$. EPS was extracted from the supernatant of cell cultures at $\mathrm{OD}_{600}=2.3$. Our results showed that exogenous addition of 3 -HBA $(4.8 \mu \mathrm{M})$ could fully restore EPS production in the $\Delta$ xanB2 strain to wild-type levels $(3.1 \mathrm{mg} / \mathrm{ml})$; higher concentrations of 3 -HBA induced the $\Delta \mathrm{xanB} 2$ strain to produce more EPS. For example, EPS at 3.8 or $4.7 \mathrm{mg} / \mathrm{ml}$ was detected in the supernatant of $\triangle \mathrm{xanB} 2$ cell cultures supplemented with 9.6 or $19.2 \mu \mathrm{M}$ 3-HBA, respectively (Fig. 2A; Supplementary Fig. S4A). The addition of 4-HBA had effects similar to those of 3-HBA on EPS production (Fig. 2A). Interestingly, the addition of both 3-HBA $(4.8 \mu \mathrm{M})$ and 4-HBA ( 4.8 $\mu \mathrm{M})$ did not show an additive effect on EPS production in cell cultures of the $\Delta$ xanB2 strain (Fig. 2A).

EPS in xanthomonads is a polymer of repeating pentasaccharide units (Sutherland 1993). The assembly of the pentasaccharide repeating unit, polymerization, and the export of EPS are directed by a gene cluster comprising 13 genes, gumB (PXO_01391) to gumN (PXO_01405) (Salzberg et al. 2008;

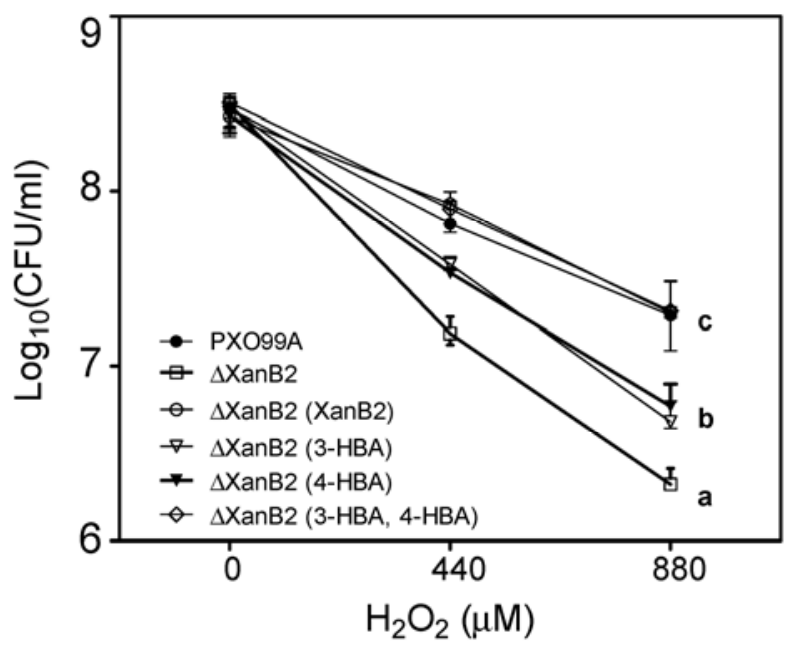

Fig. 4. $\mathrm{H}_{2} \mathrm{O}_{2}$ resistance of the Xanthomonas oryzae pv. oryzae $\mathrm{PXO} 99 \mathrm{~A}$ $\triangle \mathrm{xanB} 2$ strain in the presence of 3-hydroxybenzoic acid (3-HBA) or 4-hydroxybenzoic acid (4-HBA). Bacterial cells at an optical density at $600 \mathrm{~nm}$ of 2.0 were collected for $\mathrm{H}_{2} \mathrm{O}_{2}$ treatment. After 30 min of $\mathrm{H}_{2} \mathrm{O}_{2}$ treatment, the CFU value of each strain was determined. $($ xanB2 $)=$ complemented with a plasmid pBBRMCS1 harboring the gene $x a n B 2 .(3-\mathrm{HBA})=$ addition of 3-HBA at a final concentration of $4.8 \mu \mathrm{M}$. (4-HBA) = addition of 4-HBA at a final concentration of $38.4 \mu \mathrm{M}$. Values shown are the means \pm standard deviation from three independent experiments. Different letters indicate significant difference between treatments according to least significant difference at $P=0.05$. 
Sutherland 1993). Transcriptional analysis has revealed that the gum region is expressed mainly as an operon from a promoter located upstream of gumB (Katzen et al. 1996). In this study, by using reverse-transcription polymerase chain reaction (RT-PCR), we showed that the transcriptional levels of gumB and gumK in $x a n B 2$ deletion mutant were significantly lower than those in the wild-type strain (Fig. 2B). Overexpression of $x a n B 2$ or exogenous addition of 3-HBA $(19.2 \mu \mathrm{M})$ or $4-\mathrm{HBA}$ $(19.2 \mu \mathrm{M})$ restored the expression levels of gum B and gumK (Fig. 2B). To further investigate the effects of 3-HBA or 4-HBA on the expression of gum cluster in PXO99A, a reporter construct was created by fusing the promoter region of the gum cluster with the coding sequence for $\beta$-glucuronidase (GUS) of E. coli (gusA). The GUS activity analysis results confirmed that addition of 3-HBA $(19.2 \mu \mathrm{M})$ or 4-HBA $(19.2 \mu \mathrm{M})$ can stimulate expression of the gumgusA reporter (Fig. 2C).

\section{3-HBA and 4-HBA have a cumulative effect}

on cell viability and $\mathrm{H}_{2} \mathrm{O}_{2}$ resistance in $X$. oryzae pv. oryzae.

The exogenous addition of 3-HBA $(4.8 \mu \mathrm{g} / \mathrm{ml})$ or $4-\mathrm{HBA}$ $(38.4 \mu \mathrm{g} / \mathrm{ml})$ to the $\Delta \mathrm{xanB} 2$ strain partially restored viability (Fig. 3B; Supplementary Fig. S5). In contrast, the addition of 3-HBA $(4.8 \mu \mathrm{M})$ and 4-HBA $(4.8 \mu \mathrm{M})$ together fully restored
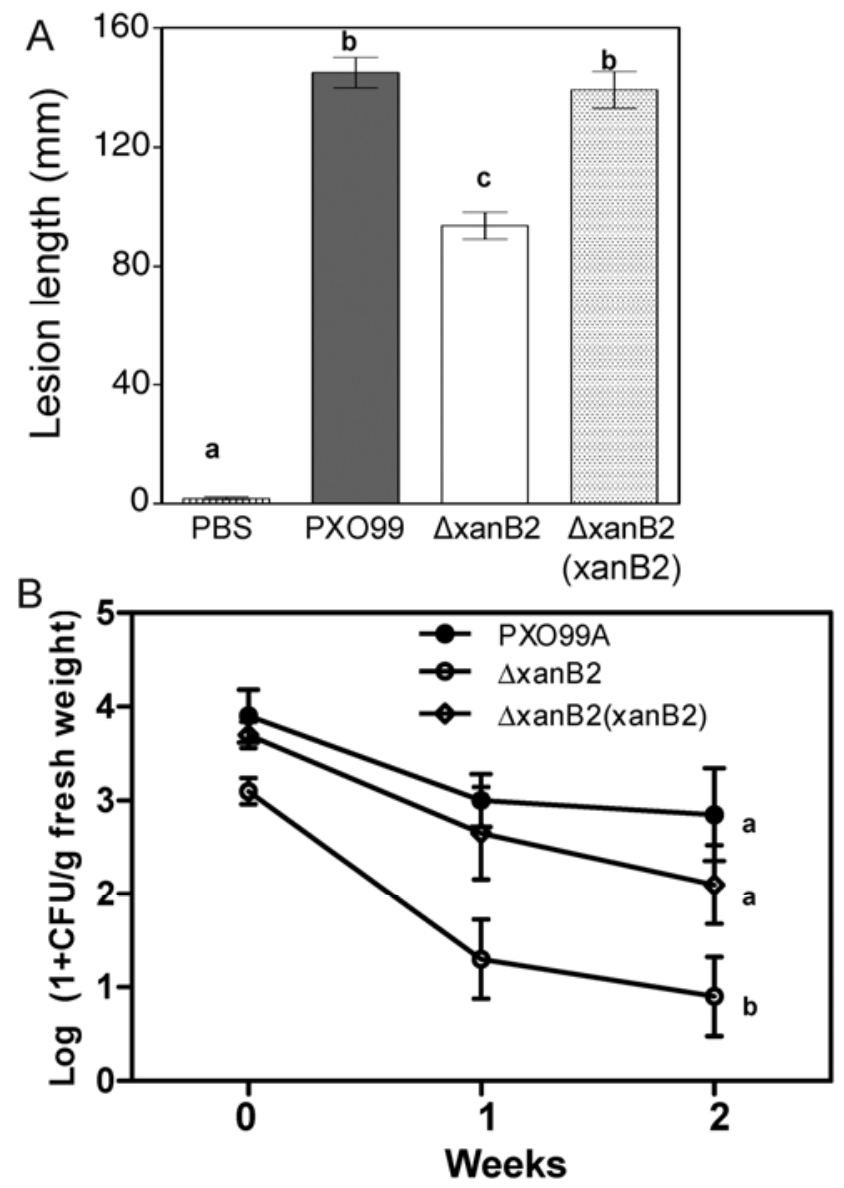

Fig. 5. Deletion of $x a n B 2$ impairs $\mathbf{A}$, virulence and $\mathbf{B}$, epiphytic survival of Xanthomonas oryzae pv. oryzae PXO99A. Adult rice plants ('Shanyou 63', 2 months old) were used in virulence assays. (xanB2) $=$ complemented with a plasmid pBBRMCS1 harboring the gene xanB2. For virulence assay, the values shown are the mean \pm standard deviation (SD) from 10 measurements of the length of the lesions induced by the bacterium on the leaves of infected rice plants. For epiphytic assay, the significant differences could also be observed for the $\mathrm{H}_{2} \mathrm{O}_{2}$ treatment at $440 \mu \mathrm{M}$. Values shown are the mean \pm SD from three independent experiments. Different letters indicate significant difference between treatments according to least significant difference at $P=0.05$. the viability of the $\Delta \mathrm{xanB} 2$ strain to wild-type levels (Fig. 3B), suggesting a cumulative effect of 3-HBA and 4-HBA on cell viability. Similarly, the addition of 3-HBA or 4-HBA only partially restored $\mathrm{H}_{2} \mathrm{O}_{2}$ resistance in the $\Delta$ xanB2 strain. However, the addition of 3-HBA and 4-HBA together fully restored $\mathrm{H}_{2} \mathrm{O}_{2}$ resistance in the $\Delta \mathrm{xanB} 2$ strain to wild-type levels (Fig. 4; Supplementary Fig. S6).

\section{XanB2-derived 4-HBA is required}

for ubiquinone biosynthesis in X. oryzae pv. oryzae PXO99A.

Ubiquinones have been found to play multiple roles in respiration, gene regulation, and oxidative stress management
A<smiles>O=C(O)c1cccc(O)c1</smiles>

(1) 3-HBA<smiles>O=C(O)c1ccc(O)cc1</smiles>

(2) 4-HBA
B
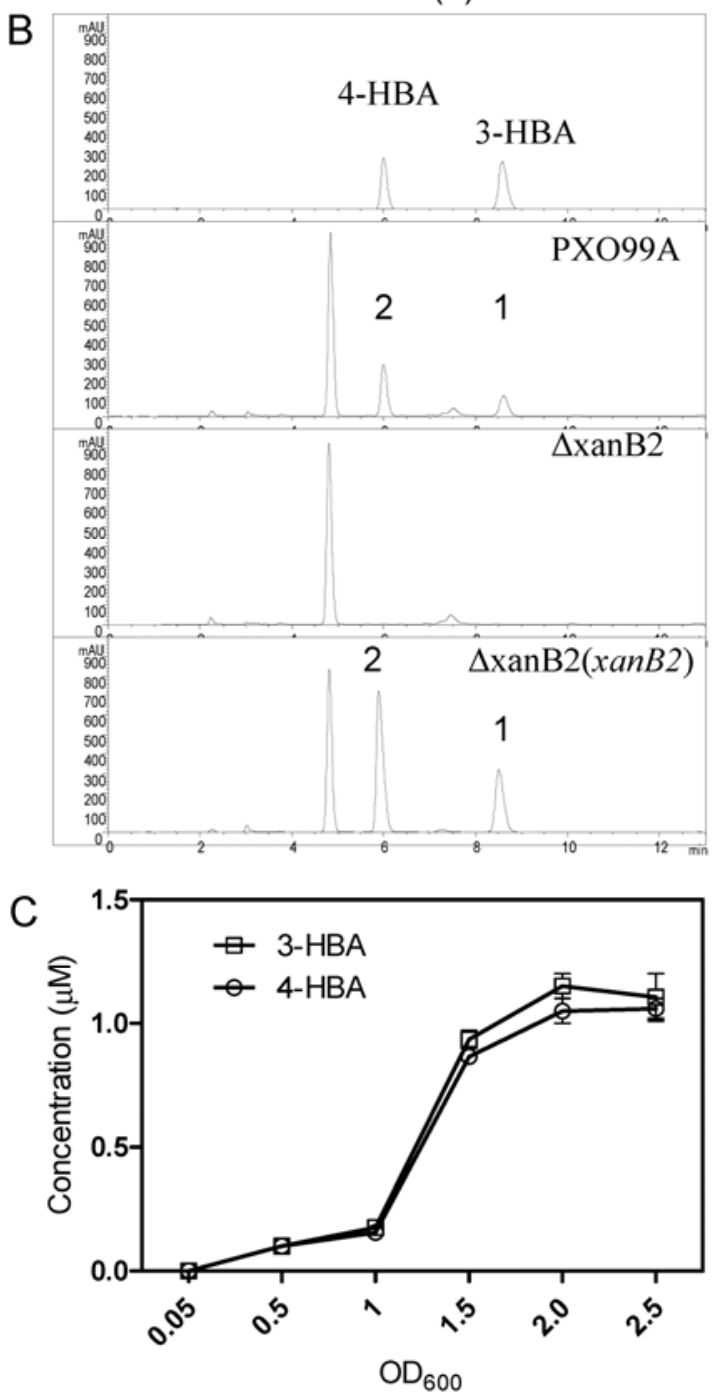

Fig. 6. Xanthomonas oryzae pv. oryzae PXO99A produces 3-hydroxybenzoic acid (3-HBA) and 4-hydroxybenzoic acid (4-HBA) via XanB2. A, Chemical structure of 3-HBA and 4-HBA. B, High-performance liquid chromatography analysis of 3-HBA and 4-HBA production in the supernatant of Xanthomonas oryzae pv. oryzae strains. C, 3-HBA and 4-HBA production during the growth cycle. $(x a n B 2)=$ complemented with a plasmid pBBRMCS1 harboring the gene $x a n B 2 . \mathrm{OD}_{600}=$ optical density at $600 \mathrm{~nm}$. 
(Sǿballe and Poole 1999). Previous findings showed that XanB2 is an alternative source of 4-HBA, and that XanB2-derived 4HBA is an essential precursor for CoQ8 biosynthesis (Zhou et al. 2013). In this study, ubiquinone was extracted and purified from $X$. oryzae pv. oryzae wild-type strain PXO99A using the method described by Zhou and associates (2013). HPLC and subsequent MS analysis revealed that the ubiquinone produced by PXO99A was CoQ8 (Fig. 7A; Supplementary Fig. S7A). The PXO99A genome contains most of the genes for ubiquinone biosynthesis—ubiA (PXO_02871), ubiB (PXO_02769), ubiE (PXO_04274), ubiF (PXO_04637), ubiG (PXO_00379), ubiH (PXO_04638), and ispB (PXO_02016)—but not the homolog of $u b i C$ or Rv2949c encoding chorismate-pyruvate lyase (Siebert et al. 1994; Stadthagen et al. 2005). Deletion of $x a n B 2$ significantly decreased CoQ8 production (Fig. 7B). Overexpression of $x a n B 2$ or exogenous addition of 4-HBA $(4.8 \mu \mathrm{M})$ to the $\Delta \mathrm{xanB} 2$ strain restored CoQ8 production to wild-type levels (Fig. 7B). Exogenous addition of 3-HBA (4.8 $\mu \mathrm{M}$ ) had no effect on CoQ8 production (Fig. 7B).

A
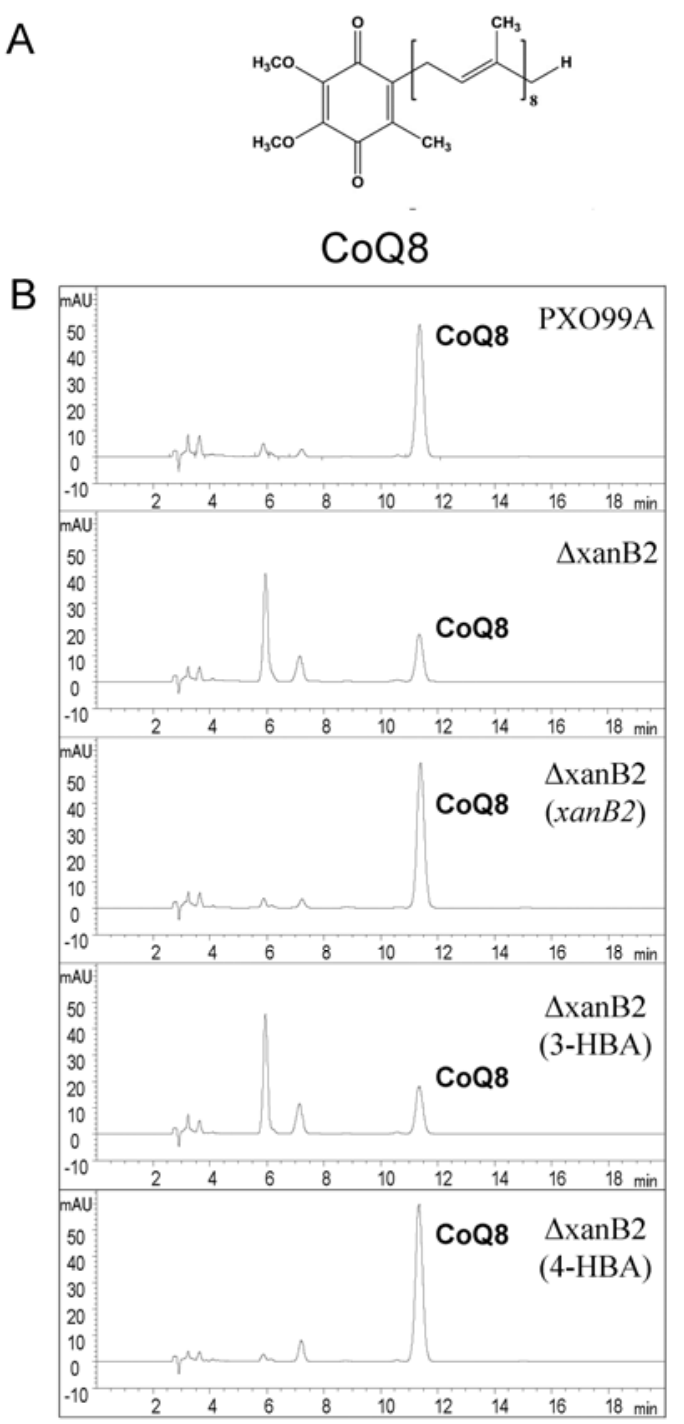

Fig. 7. $x a n B 2$ and 4-hydroxybenzoic acid (4-HBA) are required for coenzyme Q $(\mathrm{CoQ}) 8$ biosynthesis in Xanthomonas oryzae pv. oryzae PXO99A. A, Chemical structure of CoQ8. B, High-performance liquid chromatography analysis of $\mathrm{CoQ} 8$ production in $X$. oryzae pv. oryzae strains. $(x a n B 2)=$ complemented with a plasmid $\mathrm{pBBRMCS} 1$ harboring the gene $x a n B 2$. $(3-\mathrm{HBA})=$ addition of 3-hydroxybenzoic acid at a final concentration of $4.8 \mu \mathrm{M}$. (4-HBA) $=$ addition of 4-HBA at a final concentration of $38.4 \mu \mathrm{M}$

\section{PXO99A strain contains}

a degenerated 4-HBA efflux pump.

The pig clusters between $X$. campestris pv. campestris and $X$. oryzae pv. oryzae are highly conserved; however, the extracellular levels of 3-HBA and 4-HBA of $X$. campestris pv. campestris XC1 and X. oryzae pv. oryzae PXO99A are apparently different (Fig. 6C). To explore the underlying causes of the difference, we first did amino acid sequence alignment analysis and found that XanB2 in $X$. campestris pv. campestris and $X$. oryzae pv. oryzae are highly conserved, with only a few amino acids being divergent (Supplementary Fig. S8). Furthermore, we found that $X$. campestris pv. campestris $\Delta \mathrm{xanB} 2$ strains overexpressing $x a n B 2^{\text {Xoo }}$ produce significantly more 4-HBA than $X$. oryzae pv. oryzae $\Delta \mathrm{xanB} 2$ strains overexpressing $x a n B 2^{\mathrm{Xcc}}$ (Supplementary Fig. S9). These findings suggest that the differential extracellular production of 3-HBA and 4-HBA in $X$. campestris pv. campestris and $X$. oryzae pv. oryzae is not due to XanB2.

A 4-HBA efflux pump AaeXAB was characterized in $E$. coli MG1655 (Van Dyk et al. 2004) (Fig. 8A). X. campestris pv. campestris ATCC33913 contains homologs of aaeX (XCC4168), aaeA (XCC4169), and aaeB (XCC4171), as well as an additional XCC4170 encoding an outer membrane efflux protein (Fig. 8A). Deletion of the gene cluster of XCC4168 to XCC4171 in X. campestris pv. campestris XC1 resulted in decreased production of exogenous 3-HBA and 4-HBA (J.-Y. Wang, unpublished data). The PXO99A genome contains two genes, PXO_03532 and PXO_03533, in the same genomic locus (Fig. 8A). PXO_03532 and PXO_03533 are highly homologous to XCC4170 and XCC4171, respectively (Supplementary Figs. S10 and S11); however, the products of PXO_03532 and PXO_03533 (188 and 145 amino acids) are much smaller than those of XCC4170 and XCC4171 (766 and 483 amino acids) (Fig. 8A). Deletion or overexpression of both PXO_03532 and PXO_03533 had no effects on the extracellular production of 3-HBA and 4-HBA in X. oryzae pv. oryzae PXO99A (Fig. 8B and C). Overexpression of the gene cluster of XCC4168 to XCC4171 in PXO99A significantly increased the extracellular level of 3-HBA and 4-HBA (Fig. 8B and C). Collectively, these data suggest that PXO_03532 and PXO_03533 encode a degenerated 4-HBA efflux pump in PXO99A.

\section{DISCUSSION}

In this study, we showed that $\mathrm{XanB} 2$, a recently functionally characterized chorismatase in $X$. campestris pv. campestris, plays important roles in adaptation and virulence in the $X$. oryzae pv. oryzae PXO99A. PXO99A produces 3-HBA and 4-HBA via XanB2. 3-HBA is exclusively associated with xanthomonadin production while 4-HBA is mainly involved in CoQ8 biosynthesis. A high concentration of 4-HBA alone also induced atypical xanthomonadin biosynthesis. In addition, 3-HBA or 4HBA is required for full EPS production, optimal CFU values at late stationary phase, $\mathrm{H}_{2} \mathrm{O}_{2}$ resistance, and virulence. Our findings also demonstrate the $X$. oryzae pv. oryzae PXO99A produces CoQ8 via a new mechanism dependent on XanB2. XanB2 has been shown to be a bifunctional chorismatase that uses chorismate, the end product of shikimate pathway, to synthesize 3 -HBA and 4-HBA in $X$. campestris pv. campestris XC1 (Zhou et al. 2013). 3-HBA was proposed to be a biosynthetic intermediate for xanthomonadin biosynthesis (He et al. 2011). In $X$. oryzae pv. oryzae, disruption of genes encoding key components of the shikimate pathway led to deficiency in xanthomnadin biosynthesis and DF production (Goel et al. 2001; Park et al. 2009; Song et al. 2011). Therefore, the roles of XanB2 in PXO99A are generally consistent with those in $X$. campestris pv. campestris (He et al. 2011; Zhou et al. 2013). 
However, the current study also provides evidence that $X$. oryzae pv. oryzae PXO99A, compared with X. campestris pv. campestris, has evolved several specific features in 3-HBA and 4-HBA signaling. First, PXO99A produces significantly less 3-HBA and 4-HBA than $X$. campestris pv. campestris does. The maximum levels of 3-HBA and 4-HBA in the supernatant of $X$. campestris pv. campestris were previously determined to be 6.2 and $32.0 \mu \mathrm{M}$, respectively (He et al. 2011; Zhou et al. 2013), whereas the maximum levels of 3-HBA and 4-HBA produced by $X$. oryzae pv. oryzae were 1.2 and $1.1 \mu \mathrm{M}$, respectively (Fig. 6C). Our results further showed that the differential extracellular production of 3-HBA and 4-HBA in X. campestris pv. campestris and $X$. oryzae pv. oryzae is not due to XanB2 itself but is partially due to a degenerated 4-HBA efflux pump. Nearly all bacterial species have the metabolic capacity to synthesize various aromatic compounds (Gosset 2009) and they also evolve diverse transporting systems for aromatic compounds (Chaudhry et al. 2007). AaeAB is the first characterized 4-HBA efflux pump in bacteria. X. campestris pv. campestris that contains a functional AaeAB-like efflux pump (XCC4168-XCC4169) (Fig. 8A) whereas X. oryzae pv. oryzae contains a degenerated efflux pump (Fig. 8B and C). The biological significance of the degenerated 4-HBA efflux pump in PXO99A remains to be elucidated.

Second, PXO99A has evolved unique xanthomonadin induction patterns via 3-HBA and 4-HBA. In $X$. campestris pv. campestris $\mathrm{XC1}$, it was reported that exogenous addition of 3-HBA (approximately $6 \mu \mathrm{M}$ ) fully restored xanthomonadin biosynthesis in $\Delta x a n B 2$ strains to wild-type levels. The addition of more 3 -HBA (12.5 to approximately $50 \mu \mathrm{M})$ to $\Delta \mathrm{xanB} 2 \mathrm{cul}$ tures, however, failed to induce more xanthomonadin production in X. campestris pv. campestris (He et al. 2011). In contrast, in the $X$. oryzae pv. oryzae PXO99A, addition of 3-HBA $(4.8 \mu \mathrm{M})$ fully induced xanthomonadin production. Higher concentrations of 3-HBA ( 9.6 to $38.4 \mu \mathrm{M})$ significantly increased xanthomonadin production (Fig. 1C). Furthermore, it was previously shown that exogenous addition of higher concentrations of 4-HBA (100 to $1,000 \mu \mathrm{M})$ induced darker yellow xanthomonadins in X. campestris pv. campestris (He et al. 2011). Conversely, this study demonstrates that the xanthomonadins induced by addition of higher concentrations of 4-HBA (100 to $1,000 \mu \mathrm{M}$ ) are pale yellow in PXO99A (Fig. 1A).

Third, previous results by Poplawsky and Chun (1997) showed that null mutation of pigB in $X$. campestris pv. campestris B-24 abolished the production of xanthomonadins and DF and resulted in impaired production of EPS. In X. campestris pv. campestris strains 8004 and $\mathrm{XC1}$, it was found that deletion of $x a n B 2$ only slightly affected EPS production and the addition of 3-HBA had no significant effect on EPS production (He et al. 2011). The present study showed that deletion of $x a n B 2$ in $X$. oryzae pv. oryzae led to a significant decrease in EPS levels in the supernatant of PXO99A. The exogenous addition of 3-HBA $(4.8 \mu \mathrm{M})$ or 4 -HBA $(4.8 \mu \mathrm{M})$ fully restored EPS production to wild-type levels (Fig. 2). EPS production increased with the extracellular addition of 3-HBA or 4-HBA. Our results further demonstrated that XanB2, 3-HBA, or 4-HBA induces EPS production through promoting the transcriptional expression of gum cluster (Fig. 2). The mechanism behind the strain-specific EPS induction by 3-HBA or 4-HBA in $X$. campestris pv. campestris and $X$. oryzae pv. oryzae remains to be elucidated.

Taken together, our findings with $X$. oryzae pv. oryzae PXO99A further support a growing body of evidence that $\mathrm{XanB} 2$ is a key metabolic link between the shikimate pathway, xanthomonadin, and CoQ biosynthesis. The mechanisms underlying $X$. campestris pv. campestris and $X$. oryzae pv. oryzae differences in response to 3-HBA or 4-HBA remain undefined.
The yellow xanthomonadin pigments are a mixture in Xanthomonas spp.; only xanthomonadin I from X. juglandis has been chemically characterized (Andrewes et al. 1976). The detailed chemical structures of $X$. oryzae pv. oryzae and $X$. campestris pv. campestris xanthomonadins remain to be investigated. In X. campestris pv. campestris, the pig cluster, which is composed of 20 genes (XCC3995 to XCC4015), is responsible for xanthomonadin biosynthesis. In $X$. oryzae pv. oryzae, xan-
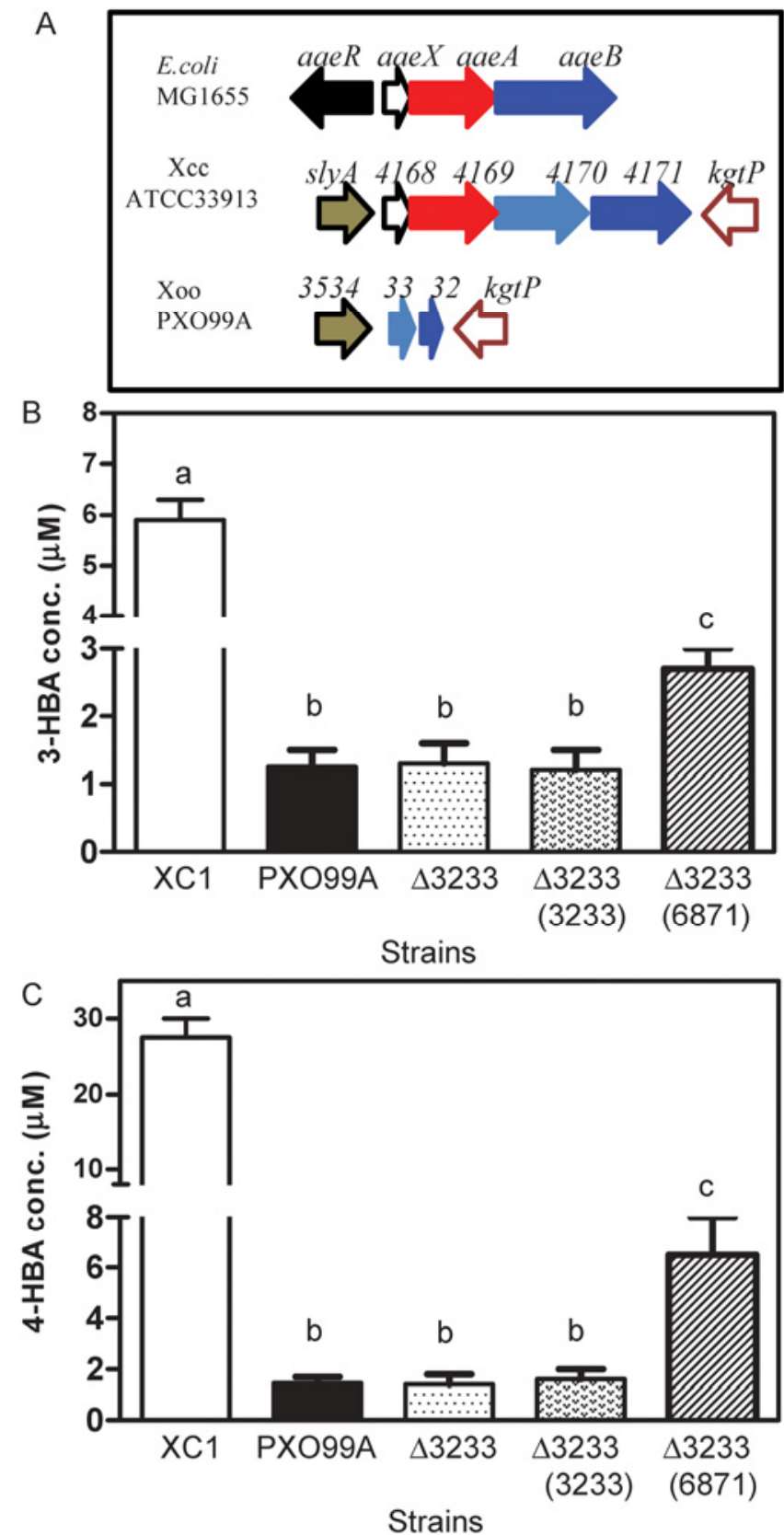

Fig. 8. Xanthomonas oryzae pv. oryzae PXO99A encodes a degenerated 4hydroxybenzoic acid (4-HBA) efflux pump. A, Genes encoding 4-HBA efflux pump in Escherichia coli, X. campestris pv. campestris, and X. oryzae pv. oryzae. B and C, Overexpression of XCC4168 to XCC4171 significantly increased exogenous 3-hydroxybenzoic acid (3-HBA) and 4HBA production in $X$. oryzae pv. oryzae PXO99A. $\Delta 3233=$ the double deletion mutant of PXO_03532 and PXO_03533. (3233) = complemented with a plasmid pBBRMCS1 harboring the genes PXO_03532 and PXO_03533. $(6871)=$ complemented with a plasmid pBBRMCS1 harboring the gene cluster XCC4168 to XCC4171. Values shown are the mean \pm standard deviation from three independent experiments. Different letters indicate significant difference between treatments according to least significant difference at $P=0.05$. 
thomonadin biosynthetic genes are clustered at two separated loci (PXO_02877 to PXO_02885 and PXO_03730 to PXO_ 03741). The $X$. oryzae pv. oryzae pig clusters contain two additional genes encoding conserved hypothetical proteins PXO_02879 and PXO_03740 and lack two genes (XCC4002 and XCC4006) identified in X. campestris pv. campestris. The relevance of how these genetic differences in the pig clusters contribute to the differential effects of 3-HBA and 4-HBA remains to be determined. Further characterization of the chemical structure of xanthomonadins in X. oryzae pv. oryzae and $X$. campestris pv. campestris will contribute to a better understanding of how 3-HBA and 4-HBA are involved in xanthomonadin biosynthesis.

The results of this study indicate that, in PXO99A, both xanthomonadin and CoQ8 biosynthesis are linked together by a single metabolic enzyme, XanB2. The membrane-bound yellowpigment xanthomonadins have been shown to play essential roles in protecting bacteria from photobiological and peroxidative damage and are important for epiphytic survival and systemic infection in Xanthomonas spp. (He et al. 2011; Jenkins and Starr 1982; Poplawsky et al. 2000; Rajagopal et al. 1997). Aerobic respiration and active plant defenses can result in increasing production of reactive oxygen species, including superoxide, $\mathrm{H}_{2} \mathrm{O}_{2}$, and $\mathrm{OH}^{-}$(Bestwick et al. 1997; Bindschedler et al. 2006; Sutherland 1991). Therefore, the ability of PXO99A to survive oxidative stress is of critical importance for successful colonization in the rice plant. Microbial ubiquinones also play roles in oxidative stress management (Sǿballe and Poole 1999). Hence, understanding the role of XanB2 in 3-HBA and 4-HBA production for use in xanthomonadins and ubiquinone biosynthesis provides new insight into factors that allow $X$. oryzae pv. oryzae to survive oxidative stress.

\section{MATERIALS AND METHODS}

\section{Bacterial strains and growth conditions.}

$X$. oryzae pv. oryzae wild-type strain PXO99A and its derivatives were grown at $28^{\circ} \mathrm{C}$ in NYG medium $(5 \mathrm{~g}$ of peptone, 3 $\mathrm{g}$ of yeast extract, and $20 \mathrm{~g}$ of glycerol, $\mathrm{pH}$ 7.0) or NAS medium $(5 \mathrm{~g}$ of peptone, $1 \mathrm{~g}$ of yeast extract, $3 \mathrm{~g}$ of beef extract, and $50 \mathrm{~g}$ of sucrose, $\mathrm{pH} 7.0$ ) in the dark. E. coli strains were grown at $37^{\circ} \mathrm{C}$ in Luria-Bertani ( $10 \mathrm{~g}$ of tryptone, $5 \mathrm{~g}$ of yeast extract, and $10 \mathrm{~g}$ of $\mathrm{NaCl}$ ) medium. Antibiotics were added at the following concentrations when required: kanamycin, 50 $\mu \mathrm{g} / \mathrm{ml}$; cephalexin, $20 \mu \mathrm{g} / \mathrm{ml}$; and ampicillin, $100 \mu \mathrm{g} / \mathrm{ml}$.

\section{Gene deletion and functional complementation analysis.}

PXO_03739 in-frame deletion mutants of $X$. oryzae pv. oryzae PXO99A were generated according to $\mathrm{He}$ and associates (2006) using the following primers: 3739D-FOR1: cgggatccag ggccgcgctggttgatg, 3739D-REV1: gtgcgtggtctgggcctgggaag, 3739D-FOR2: cccaggcccagaccacgcaccgcgatgagctggcggtggag, and 3739D-REV2: CCCAAGCTTcgegggggacgaatcagaat. For complementation analysis, the coding region of PXO_03739 was amplified by PCR using 3739-FOR: gctctagatcagccatgcac cccatcgatc and 3739-REV: ggaattcgtggcgecaccgecggc and was cloned under the control of the lac promoter in pBBR-1-MCS (Kovach et al. 1995). The resulting construct was transferred into PXO99A strain via electroporation. The PXO_3739 deletion mutant was further verified by PCR and sequencing analysis. The DNA fragment consisting of XCC4168 to XCC4171 was amplified by PCR using 416871-FOR: cccaagcttatgtggccg atgtacggagaattcag and 416871-REV: gctcagactgaggtgcgctggcgt gctttag and was cloned under the control of the lac promoter in pBBR-1-MCS. The resulting construct was transferred into strain PXO99A via electroporation. The DNA fragment consisting of PXO_03532 to PXO_03533 was amplified by PCR using 3233FOR: ggaattcGTGGCCGGCAGTGATCTGGAGA and 3233REV: cetctagaTTATCGCCCTGACGGCAGAGGGG and was cloned in pBBR-1-MCS for overexpression.

\section{Isolation of total RNA and RT-PCR analysis.}

RNA extraction and RT-PCR analysis were conducted as described previously (Zhou et al. 2011). Briefly, cells from bacterial culture grown in NAS medium at $\mathrm{OD}_{600}=1.6$ were collected by centrifugation at $4^{\circ} \mathrm{C}$ for $5 \mathrm{~min}$ at $10,000 \mathrm{rpm}$. Total RNA samples were prepared by using RNeasy midi columns following the manufacturer's instructions (Qiagen, Valencia, CA, U.S.A.). RNA integrity was confirmed by electrophoresis using a $1.3 \%$ formaldehyde agarose gel. RT-PCR analysis was conducted using a One-Step RT-PCR Kit (Qiagen) following the manufacturer's instructions. A total of $200 \mathrm{ng}$ of total RNA was used for reverse transcription.

\section{Construction of pL3gumGUS and assay of gumgusA expression in culture.}

The reporter plasmid pL3gumGUS was constructed and assayed following the methods previously described (Vojnov et al. 2001; Wang et al. 2004). Briefly, the promoter region of the gum operon (located upstream of gumB) was amplified by PCR with primers XOOGum-FOR: GGATCCGGGCAGTAATCGC GAGCTAC and XOOGum-REV: cccaagctttccgatcagtttcttcatgcgt gtg. The PCR product was cleaved and ligated into the plasmid pGEM-4-GUS to generate the intermediate construct pGEgumGUS. The gumGUS cassette was then cloned as a HindIIIEcoRI fragment into the broad-host-range vector pLAFR3 to create pL3gumGUS. The plasmid was transferred to wild-type and xanB2 mutant strains of PXO99A by triparental mating. For GUS activity assay, flasks $(250 \mathrm{ml})$ containing $50 \mathrm{ml}$ of media were inoculated with $0.5 \mathrm{ml}$ of an overnight culture of PXO99A strains diluted to an $\mathrm{OD}_{600}$ of 0.5 . The cells were collected from the culture at $\mathrm{OD}_{600}=2.0$ and the GUS activity was measured as described previously (Jefferson et al. 1987) and defined as picomoles of methyl umbelliferone produced per minute per microgram of total soluble protein.

\section{Extraction and quantification of xanthomonadins.}

The previously described procedure for the extraction of pigments from X. juglandis (Irey and Stall 1982) was used in this study, with minor modifications. Briefly, PXO99A cultures were grown until stationary phase $\left(\mathrm{OD}_{600}=2.1\right)$ was reached, and the cells from $5 \mathrm{ml}$ of culture were recovered by centrifugation (10,000 rpm for $10 \mathrm{~min})$. Pigments were extracted with $1 \mathrm{ml}$ of methanol by shaking for $5 \mathrm{~min}$ at room temperature. The amount of pigment produced was expressed as the absorbance (OD at $445 \mathrm{~nm}$ ) of crude pigment extracts (Poplawsky and Chun 1997).

Extraction, purification, and bioassay of 3-HBA and 4-HBA. X. oryzae pv. oryzae PXO99A was cultured in NAS medium for $72 \mathrm{~h}$. Bacterial supernatants (30 liters) were collected by centrifugation $\left(3,800 \mathrm{rpm}\right.$ for $30 \mathrm{~min}$ at $\left.4^{\circ} \mathrm{C}\right) .3-\mathrm{HBA}$ and $4-$ HBA were extracted and purified following a previously described method (He et al. 2011; Zhou et al. 2013).

\section{Bacterial $\mathrm{H}_{2} \mathrm{O}_{2}$ resistance test and $\mathrm{CFU}$ assay.}

$X$. oryzae pv. oryzae strains were grown in NAS medium with or without 3-HBA or 4-HBA. The $\mathrm{H}_{2} \mathrm{O}_{2}$ resistance assay and the bacterial CFU assay were conducted as previously described by $\mathrm{He}$ and associates (2011).

\section{EPS production assay.}

To analyze the production of EPS, the supernatants of bacteria cultured in NAS medium (10 ml, $\mathrm{OD}_{600}$ of approximately 2.3 ) 
were collected by centrifugation at $10,000 \mathrm{rpm}$ for $10 \mathrm{~min} . \mathrm{KCl}$ solution $(400 \mu \mathrm{l}, 3.4 \mathrm{M})$ was added to the supernatants followed by $20 \mathrm{ml}$ of absolute ethanol and incubated at $-20^{\circ} \mathrm{C}$ for a halfhour. The precipitated EPS were spun down $(10,000 \mathrm{rpm}$ for 10 min) and dried at $55^{\circ} \mathrm{C}$ overnight before determination of dry weights. Each experiment was conducted three times.

\section{Epiphytic survival and virulence test.}

All rice plants ('Shanyou 63', 2 months old) were grown and maintained in a greenhouse with 12-h day-and-night cycle illuminations by fluorescent lamps with a light intensity of approximately 50,000 to $60,0001 \mathrm{x}$. A constant temperature of $25^{\circ} \mathrm{C}$ with relative humidity at $75 \%$ was maintained. For epiphytic survival assay, the bacterial pellets from the culture at $\mathrm{OD}_{600}=1.6$ were resuspended in sterile phosphate-buffered saline (PBS) buffer to an OD of 0.1 and sprayed on adult rice leaves. Each week thereafter, the leaves were sampled for populations of $X$. oryzae pv. oryzae by plating PBS extracts on NAS agar plate with rifampicin $(25 \mu \mathrm{g} / \mathrm{ml})$, as previously described (Poplawsky and Chun 1998). The data were log transformed, and the means and the standard errors of the mean were then calculated and plotted. For the virulence assay, the bacterial pellets from the culture at $\mathrm{OD}_{600}=1.6$ were resuspended in sterile PBS buffer to an OD of 0.05 and inoculated into adult rice plants by leaf-needling for lesion length measurement. Lesion lengths were measured 14 days after inoculation. Ten leaves were inoculated for each independent experiment and each treatment was repeated three times.

\section{Ubiquinone extraction, purification, and HPLC analysis.}

Ubiquinone was extracted as previously described (Zhou et al. 2013), with slight modifications. Briefly, bacteria were grown in NAS medium until an OD of 1.6 and the cells from $50 \mathrm{ml}$ of cultures were collected by centrifugation. Cell pellets were resuspended in $2 \mathrm{ml}$ of $0.2 \mathrm{M}$ acetate buffer ( $\mathrm{pH}$ 5.6) after washing twice by $1 \times$ PBS. Cryo-impacted cell homogenate was subjected to sonication for a total of $90 \mathrm{~s}$. Hexaneacetone $(5 \mathrm{ml}, 1: 1, \mathrm{vol} / \mathrm{vol})$ reaction mixture was added to the cell homogenate followed by sonication and vortexing. The hexane fractions were collected and the solvent was removed by rotary evaporation at $40^{\circ} \mathrm{C}$ to dryness. The residue was then dissolved in $1.5 \mathrm{ml}$ of chloroform-methanol $(1: 1, \mathrm{vol} / \mathrm{vol})$, followed by washing with $0.75 \mathrm{ml}$ of $0.7 \% \mathrm{NaCl}$. The chloroform fraction was collected and the solvent was removed by rotary evaporation at $40^{\circ} \mathrm{C}$ to dryness. The residue was dissolved in $100 \mu \mathrm{l}$ of methanol. The crude extract was further analyzed by a liquid chromatographic system (Agilent 1260 Infinity; Agilent Technologies, Palo Alto, CA, U.S.A.). The eluate containing the purified ubiquinone was subjected to electrospray ionization-MS analysis on an Agilent 6230 TOF MS equipped with a Jet Stream ESI source (Agilent Technologies), using 100\% methanol containing $1.5 \%$ o formic acid as mobile phase at a flow rate of $0.2 \mathrm{ml} / \mathrm{min}$. Data were acquired under the control of Mass Hunter workstation software.

\section{Statistical analysis.}

Analysis of variance for experimental datasets was performed using JMP software (version 5.0; SAS Institute Inc., Cary, NC, U.S.A.). Significant effects of treatment were determined by the $F$ value $(P=0.05)$. When a significant $F$ test was obtained, separation of means was accomplished by Fisher's protected least significant difference at $P=0.05$.

\section{ACKNOWLEDGMENTS}

We thank B. Zhu for technical help with MS analysis. This work was supported by a grant from the National Natural Science Foundation of
China (number 31272005) and a China Postdoctoral Science Foundation Grant (number 2011M500770).

\section{LITERATURE CITED}

Andexer, J. N., Kendrew, S. G., Nur-e-Alam, M., Lazos, O., Foster, T. A., Zimmermann, A. S., Warneck, T. D., Suthar, D., Coates, N. J., Koehn, F. E., Skotnicki, J. S., Carter, G. T., Gregory, M. A., Martin, C. J., Moss, S. J., Leadlay, P. F., and Wilkinson, B. 2011. Biosynthesis of the immunosuppressants FK506, FK520, and rapamycin involves a previously undescribed family of enzymes acting on chorismate. Proc. Natl. Acad. Sci. U.S.A. 108:4776-4781.

Andrewes, A. G., Jenkins, C. L., Starr, M. P., Shepherd, J., and Hope, H. 1976. Structure of xanthomonadin I, a novel dibrominated aryl-polyene pigment produced by the bacterium Xanthomonas juglandis. Tetrahedron Lett. 45:4023-4024.

Bentinger, M., Tekle, M., and Dallner, G. 2010. Coenzyme Q-Biosynthesis and functions. Biochem. Biophys. Res. Commun. 396:74-79.

Bestwick, C. S., Brown, I. R., Bennett, M. H. R., and Mansfield, J. W. 1997. Localization of hydrogen peroxide accumulation during the hypersensitive reaction of lettuce cells to Pseudomonas syringae pv. phaseolicola. Plant Cell 9:209-221.

Bindschedler, L. V., Dewdney, J., Blee, K. A., Stone, J. M., Asai, T. Plotnikov, J., Denoux, C., Hayes, T., Gerrish, C., and Davies, D. R. 2006. Peroxidase dependent apoplastic oxidative burst in Arabidopsis required for pathogen resistance. Plant J. 47:851-863.

Bradbury, J. F. 1984. Genus II. Xanthomonas Dowson. Pages 199-210 in: Bergey's Manual of Systematic Bacteriology. N. R. Krieg and J. G. Holt, eds. Williams \& Wilkins, Baltimore.

Chaudhry, M. T., Huang, Y., Shen, X. H., Poetsch, A., Jiang, C. Y., and Liu, S. J. 2007. Genome-wide investigation of aromatic acid transporters in Corynebacterium glutamicum. Microbiology 153:857-865.

Chun, W., Cui, J., and Poplawsky, A. R. 1997. Purification, characterization and biological role of a pheromone produced by Xanthomonas campestris pv. campestris. Physiol. Mol. Plant Pathol. 51:1-14.

Cluis, C. P., Burja, A. M., and Martin, V. J. 2007. Current prospects for the production of coenzyme Q10 in microbes. Trends Biotechnol. 25:514521.

da Silva, A. C., Ferro, J. A., Reinach, F. C., Farah, C. S., Furlan, L. R., Quaggio, R. B., Monteiro-Vitorello, C. B., Van Sluys, M. A., Almeida, N. F., Alves, L. M., do Amaral, A. M., Bertolini, M. C., Camargo, L. E., Camarotte, G., Cannavan, F., Cardozo, J., Chambergo, F., Ciapina, L. P., Cicarelli, R. M., Coutinho, L. L., Cursino-Santos, J. R., El-Dorry, H., Faria, J. B., Ferreira, A. J., Ferreira, R. C., Ferro, M. I., Formighieri, E. F., Franco, M. C., Greggio, C. C., Gruber, A., Katsuyama, A. M., Kishi, L. T., Leite, R. P., Lemos, E. G., Lemos, M. V., Locali, E. C., Machado, M. A., Madeira, A. M., Martinez-Rossi, N. M., Martins, E. C., Meidanis, J., Menck, C. F., Miyaki, C. Y., Moon, D. H., Moreira, L. M., Novo, M. T., Okura, V. K., Oliveira, M. C., Oliveira, V. R., Pereira, H. A., Rossi, A., Sena, J. A., Silva, C., de Souza, R. F., Spinola, L. A., Takita, M. A., Tamura, R. E., Teixeira, E. C., Tezza, R. I., Trindade dos Santos, M., Truffi, D., Tsai, S. M., White, F. F., Setubal, J. C., and Kitajima, J. P. 2002. Comparison of the genomes of two Xanthomonas pathogens with differing host specificities. Nature 417:459-463.

Dosselaere, F., and Vanderleyden, J. 2001. A metabolic node in action: Chorismate-utilizing enzymes in microorganisms. Crit. Rev. Microbiol. 27:75-131.

Goel, A. K., Rajagopal, L., and Sonti, R. V. 2001. Pigment and virulence deficiencies associated with mutations in the aroE gene of Xanthomonas oryzae pv. oryzae. Appl. Environ. Microbiol. 67:245-250.

Gosset, G. 2009. Production of aromatic compounds in bacteria. Curr. Opin. Biotechnol. 20:651-658.

He, Y. W., Xu, M., Lin, K., Ng, Y. J., Wen, C. M., Wang, L. H., Liu, Z. D., Zhang, H. B., Dong, Y. H., Dow, J. M., and Zhang, L. H. 2006. Genome scale analysis of diffusible signal factor regulon in Xanthomonas campestris pv. campestris: Identification of novel cell-cell communicationdependent genes and functions. Mol. Microbiol. 59:610-622.

He, Y. W., Wu, J., Zhou, L., Yang, F., He, Y. Q., Jiang, B. L., Bai, L., Xu, Y., Deng, Z., Tang, J. L., and Zhang, L. H. 2011. Xanthomonas campestris diffusible factor is 3-hydroxybenzoic acid and associated with xanthomonadin biosynthesis, cell viability, antioxidant activity and systemic invasion. Mol. Plant-Microbe Interact. 24:948-957.

Herrmann, K. M., and Weaver, L. M. 1999. The shikimate pathway. Annu. Rev. Plant. Physiol. Plant. Mol. Biol. 50:473-503.

Irey, M. S. and Stall, R. E. 1982. Value of xanthomonadins for identification of pigmented Xanthomonas campestris pathovars. Pages 85-95 in: Proceedings of the Fifth International Conference on Plant Pathogenic Bacteria. August 16-23. International Center for Tropical Agriculture, Cali, Columbia. 
Jefferson, R. A., Kavanagh, T. A., and Bevan, M. W. 1987. GUS fusions: Beta-glucuronidase as a sensitive and versatile gene fusion marker in higher plants. EMBO (Eur. Mol. Biol. Organ.) J. 6:3901-3907.

Jenkins, C. L., and Starr, M. P. 1982. The brominated aryl-polyene (xanthomonadin) pigments of Xanthomonas juglandis protect against photobiological damage. Curr. Microbiol. 7:323-326.

Katzen, F., Becker, A., Zorreguiera, A., Puhler, A., and Ielpi, L. 1996. Promoter analysis of the Xanthomonas campestris pv. campestris gum operon directing biosynthesis of the xanthan polysaccharide. J. Bacteriol. 178:4313-4318.

Kovach, M. E., Elzer, P. H., Hill, D. S., Robertson, G. T., Farris, M. A., Roop, R. M., II, and Peterson, K. M. 1995. Four new derivatives of the broad-host-range cloning vector pBBR1MCS, carrying different antibiotic-resistance cassettes. Gene. 166:175-176.

Leyns, F., De Cleene, M., Swings, J., and de Ley, J. 1984. The host range of the genus Xanthomonas. Bot. Rev. 50:308-355.

Martin, S. F., Burón, I., Espinosa, J. C., Castilla, J., Villalba, J. M., and Torres, J. M. 2007. Coenzyme Q and protein/lipid oxidation in a BSEinfected transgenic mouse model. Free Radic. Biol. Med. 42:17231729

Meganathan, R. 2001. Ubiquinone biosynthesis in microorganisms. FEMS (Fed. Eur. Microbiol. Soc.) Microbiol. Lett. 203:131-139.

Nino-Liu, D. O., Ronald, P. C., and Bogdanove, A. J. 2006. Xanthomonas oryzae pathovars: Model pathogens of a model crop. Mol. Plant Pathol. 7:303-324.

Park, Y. J., Song, E. S., Noh, T. H., Kim, H., Yang, K. S., Hahn, J.H., Kang, H. W., and Lee, B. M. 2009. Virulence analysis and gene expression profiling of the pigment-deficient mutant of Xanthomonas oryzae pathovar oryzae. FEMS (Fed. Eur. Microbiol. Soc.) Microbiol. Lett. 301:149-155.

Poplawsky, A. R., and Chun, W. 1997. PigB determines a diffusible factor needed for extracellular polysaccharide slime and xanthomonadin production in Xanthomonas campestris pv. campestris. J. Bacteriol. 179:439-444.

Poplawsky, A. R., and Chun, W. 1998. Xanthomonas campestris pv. campestris requires a functional pigB for epiphytic survival and host infection. Mol. Plant-Microbe Interact. 11:466-475.

Poplawsky, A. R., Urban, S. C., and Chun, W. 2000. Biological role of xanthomonadin pigments in Xanthomonas campestris pv. campestris. Appl. Environ. Microbiol. 66:5123-5127.

Poplawsky, A. R., Walters, D. M., Rouviere, P. E., and Chun, W. 2005. A gene for a dioxygenase-like protein determines the production of the DF signal in Xanthomonas campestris pv. campestris. Mol. Plant Pathol. 6:653-657.

Rajagopal, L., Sundari, C. S., Balasubramanian, D., and Sonti, R. V. 1997. The bacterial pigment xanthomonadin offers protection against photodamage. FEBS (Fed. Eur. Biochem. Soc.) Lett. 415:125-128.

Salzberg, S. L., Sommer, D. D., Schatz, M. C., Phillippy, A. M., Rabinowicz, P. D., Tsuge, S., Furutani, A., Ochiai, H., Delcher, A. L., Kelley, D., Madupu, R., Puiu, D., Radune, D., Shumway, M., Trapnell, C., Aparna, G., Jha, G., Pandey, A., Patil, P. B., Ishihara, H., Meyer, D. F., Szurek, B., Verdier, V., Koebnik, R., Dow, J. M., Ryan, R. P., Hirata, H., Tsuyumu, S., Won Lee, S., Seo, Y. S., Sriariyanum, M., Ronald, P. C., Sonti, R. V., Van Sluys, M. A., Leach, J. E., White, F. F., and
Bogdanove, A. J. 2008. Genome sequence and rapid evolution of the rice pathogen Xanthomonas oryzae pv. oryzae PXO99A. BMC Genomics 9:204.

Siebert, M., Severin, K., and Heide, L. 1994. Formation of 4-hydroxybenzoate in Escherichia coli: Characterization of the $u b i C$ gene and its encoded enzyme chorismate pyruvate-lyase. Microbiology 140:897-904.

Sǿballe, B., and Poole, R. K. 1999. Microbial ubiquinones: Multiple roles in respiration, gene regulation and oxidative stress management. Microbiology 145:1817-1830.

Song, E. S., Park, Y. J., Noh, T. H., Kim, Y. T., Kim, J. G., Cho, H., and Lee, B. M. 2011. Functional analysis of the aroC gene encoding chorismate synthase from Xanthomonas oryzae pathovar oryzae. Microbiol. Res. 167:326-331.

Stadthagen, G., Korduláková, J., Griffin, R., Constant, P., Bottová, I., Barilone, N., Gicquel, B., Daffé, M., and Jackson, M. 2005. p-Hydroxybenzoic acid synthesis in Mycobacterium tuberculosis. J. Biol. Chem. 280:40699-40706.

Starr, M. P. 1981. The genus Xanthomonas. Pages 742-763 in: The Prokaryotes, Vol. 1. M. P. Starr, H. Stolp, H. G. Trüper, A. Balows, and H. G. Schlegel, eds. Springer Verlag, Berlin.

Starr, M. P., Jenkins, C. L., Bussey, L. B., and Andrewes, A. G. 1977. Chemotaxonomic significance of the xanthomonadins, novel brominated aryl-polyene pigments produced by bacteria of the genus Xanthomonas. Arch. Microbiol. 113:1-9.

Stephens, W. L., and Starr, M. P. 1963. Localization of carotenoid pigment in the cytoplasmic membrane of Xanthomonas juglandis. J. Bacteriol. 86:1070-1074.

Sutherland, I. W. 1993. Xanthan. Pages 363-338 in: Xanthomonas. J. G. Swings and E. L. Civerolo, eds. Chapman and Hall, London.

Sutherland, M. W. 1991. The generation of oxygen radicals during host plant responses to infection. Physiol. Mol. Plant Pathol. 39:79-93.

Van Dyk, T. K., Templeton, L. J., Cantera, K. A., Sharpe, P. L., and Sariaslani, F. S. 2004. Characterization of the Escherichia coli AaeAB efflux pump: A metabolic relief valve? J. Bacteriol. 186:7196-204.

Van Lanen, S. G., Lin, S., and Shen, B. 2008. Biosynthesis of the enediyne antitumor antibiotic C-107 involves a new branching point in chorismate metabolism. Proc. Natl. Acad. Sci. U.S.A. 105:494-499.

Vojnov, A. A., Slater, H., Daniels, M. J., and Dow, J. M. 2001. Expression of the gum operon directing xantham biosynthesis in Xanthomonas campestris and its regulation in planta. Mol. Plant Pathol. Interact. 14:768-774.

Wang, L. H., He, Y. W., Gao, Y., Wu, J. E., Dong, Y. H., He, C., Wang, S X., Weng, L. X., Xu, J. L., Tay, L., Fang, R. X., and Zhang, L. H. 2004. A bacterial cell-cell communication signal with cross-kingdom structural analogues. Mol. Microbiol. 51:903-912.

Zhou, L., Vorholter, F. J., He, Y. Q., Jiang, B. L., Tang, J. L., Xu, Y., Puhler, A., and He, Y. W. 2011 Gene discovery by genome-wide CDS re-prediction and microarray-based transcriptional analysis in phytopathogen Xanthomonas campestris. BMC Genomics 12:359.

Zhou, L. Wang, J. Y., Wang, J., Poplawsky, A., Lin, S., Zhu, B., Chang, C. Zhou, T., Zhang, L. H., and He, Y. W. 2013. The diffusible factor (DF) synthase XanB2 is a bifunctional chorismatase that links the shikimate pathway to ubiquinone and xanthomonadins biosynthetic pathways. Mol. Microbiol. 87:80-93. 